\title{
Speech and Sound Quality Recognition in Adults Bimodal Cochlear Implant Listeners
}

\author{
Leehwa Park ${ }^{1,2}$, Soo Hee Oh¹,2 \\ 'Department of Audiology and Speech Language Pathology, Hallym Univesity of Graduate Studies, Seoul, Korea \\ ${ }^{2}$ Center for Hearing and Speech Research, Hallym University of Graduate Studies, Seoul, Korea
}

Received: February 26, 2021

Revised: March 18, 2021

Accepted: March 19, 2021

Correspondence:

Soo Hee Oh, PhD

Department of Audiology and

Speech Language Pathology,

Hallym Univesity of Graduate Studies,

427 Yeoksam-ro, Gangnam-gu,

Seoul 06197, Korea

Tel: +82-70-8680-6901

Fax: +82-2-3453-6618

E-mail: osh503@naver.com
Purpose: Recent bimodal studies identified a lack of bimodal evaluation and fitting protocols to improve bimodal benefits. The purpose of this study is to measure bimodal benefits in speech and sound quality recognition and identify bimodal fitting issues with adult cochlear implant listeners to establish bimodal fitting guidelines and evaluation protocol. Methods: A total of 20 adult cochlear implant users were participated in this study. The experimental procedures included basic evaluation, hearing aid evaluation, and bimodal benefits evaluation. In order to evaluate bimodal benefits, speech and sound quality recognition tests were performed. Matrix sentences in quiet and noise (5 and $10 \mathrm{~dB}$ sound pressure level), consonant-vowel-consonant words, and story comprehension tasks were provided. Participants judged sound qualities for six sound quality dimensions and a tester performed real ear measurements to verify hearing aid gains. Results: Results showed that bimodal listeners had some bimodal benefits in the sentence and monosyllabic word recognition in quiet. The benefits of sound quality judgments were also observed for six sound quality dimensions. Bimodal cochlear implant listeners of this study demonstrated less real-ear insertion gains than target gains across test frequencies. Conclusion: Speech and sound quality recognition tests are useful tools to measure bimodal benefits. Additional care for bimodal listeners is needed to optimize bimodal fitting and improve the quality of bimodal hearing aid fitting services.

Key Words: Bimodal listeners, Bimodal benefits, Bimodal fitting, Bimodal fitting protocol.

\section{INTRODUCTION}

바이모달은 인공와우의 전기자극과 보청기의 음향자극을 통 합하여 듣는 형태로, 중복과 보완의 단서를 통해 말지각 및 음 악지각을 포함하여 다양한 측면에서 그 혜택을 보였으며 $(\mathrm{Ch}-$ ing et al., 2004; Devocht et al., 2017; Dorman et al., 2008; Farinetti et al., 2015; Kong et al., 2005; Kong \& Carlyon, 2007; Van Loon et al., 2017; Yoon et al., 2015), 성인과 아동 인공와우 사용자의 약 $32 \%$ 와 $26 \%$ 가 반대편 귀에 보청기를 착 용하는 것으로 보고된 바 있다(Scherf et al., 2014). 바이모달 착용 효과는 연구마다 차이가 있는데 이에 영향을 미칠 수 있 는 요인으로 양 귀 간 음조위상의 불일치, 개인별 잔존 청력의 차이, 이형기기 간 정보 통합 능력, 바이모달 적합, 양 귀 간 소 리 크기의 균형 등이 있다(Veugen et al., 2016).

(c) This is an Open Access article distributed under the terms of the Creative Commons Attribution Non-Commercial License (https://creativecommons.org/licenses/by-nc/4.0) which permits unrestricted non-commercial use, distribution, and reproduction in any medium, provided the original work is properly cited.
이 중 바이모달 평가 및 적합 지침과 관련하여 최근 그 중요 성이 제기되고 있으나(Veugen et al., 2016; Vroegop et al., 2019) 아직까지 적절한 적합 지침과 평가 프로토콜이 확립되지 않았고, Vroegop et al.(2018)은 바이모달 사용자의 결과 향상 을 위해 적절한 바이모달 적합 지침의 필요성을 강조하였다. 현 재까지 보고된 보청기 제조사 중심의 바이모달 적합 지침 $\left(\mathrm{Av}^{-}\right.$ danced Bionics, 2016; Cochlear Limited, 2017; Oticon, 2015) 에서는 주로 보청기 주파수 범위 설정, 양 기기 간 소리 크기의 균형, 바이모달 적합 효과 확인 등의 내용을 포함하고 있다. 또 한 바이모달 적합이 필요함에도 불구하고 실제 바이모달 적합 시행에는 차이가 있는 것으로 보고되었으며(Siburt \& Holmes, 2015), Warren \& Dunbar(2018)에 따르면 연구에 참여한 바이모 달 사용자(31명)의 $81 \%$ 가 보청기 조절에 문제가 있었음을 보고 하였다.

최근 바이모달 보청기 적합 문헌고찰(Vroegop et al., 2018) 의 내용을 살펴보면, 바이모달 보청기 적합 시 최적의 보청기 주파수 대역 결정과 양 귀 간 음량 평형에 대한 고려가 필요하 
며 주파수 전위 방식이나 보청기 적합 공식에 따른 큰 차이는 나타나지 않는 것으로 설명하였다. 바이모달 적합 지침에 활용 하기 위해 Bahng \& Oh(2020)의 문헌고찰을 근거로 바이모달 적합 과정 및 평가 요소를 정리하면 다음과 같다. 먼저 바이모 달 사용자를 대상으로 사전 평가를 시행한다. 사전 평가는 순 음 및 어음 청력 검사, 조용한 상황과 소음 상황의 말지각 검사, 설문을 포함한다. 사전 평가 후 보청기 적합과 인공와우 적합 을 점검한다. 인공와우 적합 측면에서는 먼저 인공와우 적합이 안정적이고 적절한지에 대한 점검이 필요하다. 또한 대상자가 사용하고 있는 인공와우 주파수 범위를 확인하고 인공와우 착 용 후 청력 검사 결과를 확인한다. 바이모달 보청기 적합 측면 에서는 보청기 적합 공식을 선정하고, 실이 측정과 음량 균형에 근거한 이득 조절 및 미세 조정을 시행한다. 또한 보청기 주파 수 범위를 결정하고 필요 시 와우 사영역 검사(Moore et al., 2000; Moore \& Alcántara, 2001)를 시행하여 주파수 대역을 결정한다. 인공와우와 보청기를 착용한 양 귀 간의 음량 균형 에 대한 확인은 인공와우의 적합이 편안하고 안정적일 경우 인 공와우의 음량을 기준으로 양 귀 간의 전반적인 음량 균형을 판단하도록 한다. 양 귀 간 음량 균형이 이루어지지 않은 경우 균형이 이루어지도록 보청기의 이득을 조절한다. 바이모달 적 합 후 효과 측정은 바이모달 또는 양 귀 인공와우 착용 여부를 판단하기 위해 중요한 과정으로 조용한 상황과 소음 상황에서
의 말지각 검사, 기능이득 검사, 실이 측정, 방향성 검사 등을 시행한다. 또한 음질 검사, 주관적 만족도 설문 등을 시행하여 주관적 측면에서의 바이모달 결과 향상을 확인할 수 있다.

바이모달 적합 지침은 위에서 언급한 사전 검사, 보청기 적 합, 인공와우 적합, 양 기기 간 음량 균형, 객관적 및 주관적 사 후 평가의 내용으로 구성될 수 있다. 현재 대부분의 인공와우 적합이 병원에서 시행되고 있는 점을 고려할 때 병원이 아닌 곳에서 시행하는 바이모달 적합은 주로 보청기 적합에 좀 더 비중을 두어야 할 것으로 생각되며 보청기 적합을 중심으로 바 이모달 사용자에 대한 보다 체계적인 적합과 사후관리에 대한 지침 또한 필요할 것이다. 바이모달 지침 마련을 위해서는 먼저 바이모달 혜택을 측정할 수 있는 적절한 검사를 시행하는 것이 중요한데 바이모달 혜택 여부에 따라 사용자가 향후 바이모달 과 양 귀 인공와우를 결정하는 중요한 근거가 될 수 있기 때문 이다. 본 연구에서는 먼저 바이모달 평가와 적합관리 지침 마련 을 위해 다양한 검사 조건하에서 바이모달 혜택을 확인하고자 한다. 특히 기존 연구에서 주로 사용한 조용한 상황과 소음 상 황의 문장 검사, 단음절 검사 및 주관적 효과 측정의 하나인 음 질 검사를 시행하여 이를 바이모달 검사 지침에 활용 가능성 을 파악하고자 한다. 또한 바이모달 사용자의 보청기 적합 상 태를 파악하여 바이모달 혜택 향상에서 바이모달 적합의 중요 성을 알아보고자 하였다. 이를 위해서 첫째, 성인 인공와우 사

Table 1. Participants' description

\begin{tabular}{|c|c|c|c|c|c|c|}
\hline Type & Age, yr & Sex & CI (ear) & Duration of CI use & HA (ear) & Duration of HA use \\
\hline $\mathrm{BM}$ & 33 & Male & Rondo 2 (L) & 6 months & Unitron Tempus Moxi (R) & 8 years \\
\hline $\mathrm{BM}$ & 48 & Female & Nucleus 7 (L) & 1 year 9 months & Beltone Amaze $17(\mathrm{R})$ & 8 years \\
\hline $\mathrm{BM}$ & 24 & Female & Naida Q90 (L) & 13 years 8 months & Phonak Naida Q (R) & More than 13 years \\
\hline BM & 46 & Female & Freedom (L) & 13 years 7 months & Beltone Amaze $17(\mathrm{R})$ & 14 years \\
\hline $\mathrm{BM}$ & 54 & Male & Opus $2(\mathrm{~L})$ & 8 years 7 months & ReSound (R) & 8 years \\
\hline $\mathrm{BM}$ & 54 & Female & Nucleus 7 (R) & 2 years 3 months & Beltone Amaze 17 (L) & 15 years \\
\hline $\mathrm{BM}$ & 40 & Female & Sonnet (R) & 2 years 3 months & Beltone Booster Plus 695 (L) & 16 years \\
\hline $\mathrm{BM}$ & 46 & Female & Rondo (L) & 4 months & ReSound/Linx (R) & More than 20 years \\
\hline $\mathrm{BM}$ & 25 & Female & Naida (R) & 15 years 2 months & Phonak Naida Q (L) & 23 years \\
\hline $\mathrm{BM}$ & 53 & Male & Kanso (R) & 4 years 3 months & Starkey Sound Lens sp3200 (L) & 24 years \\
\hline $\mathrm{BM}$ & 38 & Female & Nucleus 5 (R) & 8 years 7 months & Beltone Amaze 17 (L) & 34 years \\
\hline $\mathrm{BM}$ & 56 & Male & Nucleus 7 (R) & 8 years 4 months & Beltone Ally 3 (L) & 8 years 10 months \\
\hline $\mathrm{BM}$ & 45 & Female & Nucleus 7 (R) & 6 months & Beltone Alley $2(\mathrm{~L})$ & 2 years 1 month \\
\hline $\mathrm{CI}$ & 45 & Female & Nucleus 7 (R) & 1 year 8 months & Widex BEYOND & - \\
\hline $\mathrm{CI}$ & 34 & Male & Nucleus 5 (R) & 11 years 2 months & Rionet HB-37S & - \\
\hline $\mathrm{CI}$ & 48 & Female & Nucleus 6 (L) & 13 years & Rionet HB-37S & - \\
\hline $\mathrm{CI}$ & 56 & Male & Freedom (R) & 14 years 7 months & Rionet HB-37S & - \\
\hline $\mathrm{CI}$ & 37 & Female & Naida 70 (R) & 15 years 2 months & Rionet HB-37S & - \\
\hline CI & 41 & Male & Rondo 2 (R) & 1 year & Rionet HB-37S & - \\
\hline $\mathrm{CI}$ & 31 & Female & Freedom (R) & 15 years 8 months & Rionet HB-37S & - \\
\hline
\end{tabular}

BM: bimodal, CI: cochlear implant, HA: hearing aid, L: left, R: right 
용자를 대상으로 말지각과 음질 검사를 시행하고 바이모달 착 용 혜택을 측정하고 둘째, 보청기 실이 측정을 통해 바이모달 사용자의 보청기 적합 상태를 확인하였다.

\section{MATERIALS AND METHODS}

\section{연구 대상}

인공와우 착용 성인 20 명이 연구에 참여하였다. 이 중 13 명 은 바이모달, 7명은 편측 인공와우 사용자였으며 나이는 평균 42.75세(24 56세)로 남성 7명, 여성 12명이었다. 인공와우 착용 기간은 평균 85.89개월(4 182개월)로 바이모달 사용자의 보청 기 착용 기간은 평균 179.92 개월(25 408개월)이었다. 편측 인공 와우 사용자들의 수술 전 보청기 착용 기간은 평균 174.5 개월 (0 240개월)이었다. 온라인 광고를 통해 연구 참여자를 모집하 였고 연구 참여 후 소정의 사례비를 지급하였다. 참여 대상자 들의 기본 정보와 각 검사 조건에서의 청력역치 평균은 각각 Table 1과 Figure 1에서 보여준다. 본 연구는 한림국제대학원대
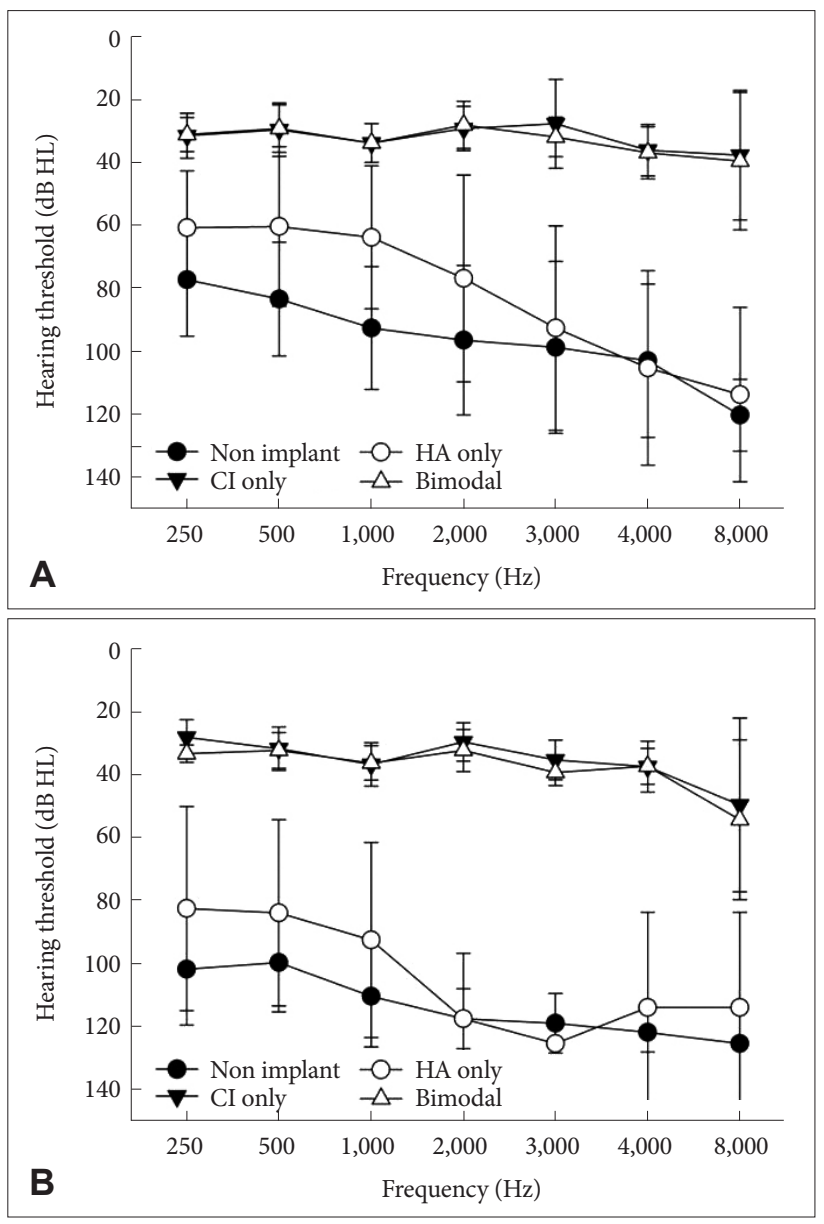

Figure 1. Mean aided and unaided hearing thresholds across test conditions. A: Bimodal subject, B: Unilateral $\mathrm{Cl}$ subject. Cl: cochlear implant, HA: hearing aid.
학교 생명윤리심의위원회의 승인을 받아 시행하였다(HUGSAUD509467).

\section{연구 방법}

검사는 사전 검사, 보청기 분석 및 적합 확인, 바이모달 효과 에 대한 평가의 순으로 시행하였다. 사전 검사에서는 대상자가 검사에 대한 설명을 듣고 동의서와 배경 정보 관련 설문을 작성 한 뒤 방음실에서 순음 및 어음청력검사, 기능이득검사, 와우 사 영역 검사(threshold-equalizing noise test)를 시행하였다(GSI Audiostar pro, Grason Stadler Inc., Eden Prairie, MN, USA). 와우 사영역 검사에서는 $500,750,1,000,1,500,3,000,4,000 \mathrm{~Hz}$ 주파수의 순음과 스펙트럼 형태의 광대역 소음을 제시하였다 (Moore et al., 2004).

보청기 분석과 적합 확인 단계에서는 Fonix 8000 (Frye Electronics, Inc., Beaverton, OR, USA)을 사용하여 보청기 성능 분석과 실이 측정을 시행하였다. 편측 인공와우 사용자의 경우 또는 바이모달 대상자 중 본인의 보청기 적합에 문제가 있다고 보고한 경우 Beltone Amaze 17 (Beltone, Ballerup, Denmark), RIONET HB-37S (Rion, Tokyo, Japan), 또는 Widex BEYOND (Widex, Lynge, Denmak) 보청기를 사용하여 대상 자의 청력에 근거한 보청기 적합 후 실이 측정을 시행하였다. 보 청기 실이 측정은 National Acoustic Laboratories' nonlinear fitting procedure, version 1 (NAL-NL1) 적합 공식(Byrne et al., 2001)을 적용하여 50, 65, 그리고 $80 \mathrm{~dB}$ sound pressure level (SPL)의 입력음을 제시한 상태에서 시행하였다. 보청기 적합을 시행한 경우 대상자의 청력역치를 기준으로 National Acoustic Laboratories' nonlinear fitting procedure, version 2 (NAL-NL2) 보청기 적합 공식(Keidser et al., 2011)을 적용하 였다. 또한, 보통 크기의 말소리와 $500 ~ 4,000 \mathrm{~Hz}$ 의 소음 제시 상황에서 대상자가 음량과 음질에 대해 판단하도록 한 뒤 대상 자의 주관적 판단을 근거로 주파수별 이득을 듣기 편안한 수준 으로 조절하였다.

\section{연구 절차}

바이모달 효과에 대한 평가 단계에서는 보청기, 인공와우, 바 이모달의 3 개 착용 조건을 무작위 순서로 진행하였다. 각 조건 에서 조용한 상황과 소음 상황 $[5,10 \mathrm{~dB}$ signal to noise ratio $(\mathrm{SNR})]$ 의 문장 검사, 조용한 상황의 단음절 검사, 이야기 이해 검사 및 음질 검사를 시행하였다. 자극음은 대상자의 $1 \mathrm{~m}$ 정면 에 위치한 스피커를 통해 $65 \mathrm{~dB} \mathrm{SPL}$ 로 제시되었다. 문장 검사는 여성 화자의 한국어 Matrix 문장 검사도구(Kim \& Lee, 2018)를 사용하여 조용한 상황과 $5 \mathrm{~dB} \mathrm{SNR}$ 및 $10 \mathrm{~dB} \mathrm{SNR}$ 소음 상황 에서 검사하였고 배경 소음은 단일 남성 화자를 사용하였다. 
단음절 검사는 자음지각검사(Korean consonant perception test, KCPT) (Kim et al., 2011)의 consonant-vowel-consonant 단어를, 이야기 이해 검사는 이야기를 듣고 질문에 답하는 이 야기 검사 도구(Lim \& Bahng, 2016)를 사용하였다. 본 검사에 서는 제시되는 문장이나 단어를 듣고 따라 말하거나 이야기를 듣고 이야기의 내용에 대한 질문에 답하도록 하였고, 1 2개의 연 습 문항을 시행하여 검사에 대한 이해를 돕도록 하였다. 주관적 음질 검사에서는 10 20초 내외의 바이올린 연주 소리, 여성 소 프라노 음성 노래, 남성 베이스 음성 노래, 냉장고 소리를 제시하 였다. 대상자는 각 소리를 듣고 설문지의 6가지 항목인 부드러 움, 명료함, 풍부함, 거리감, 쾌적함, 전반적인 느낌에 대한 주관적 인 음질 판단을 $0 ~ 10$ 까지의 해당 점수에 표시하도록 하였다.

\section{통계 분석}

각 조건별 말지각 검사와 음질 검사 값에 대한 정규성 검정 (Shapiro-Wilk's)을 시행하여 정규 분포되어 있지 않은 경우( $p<$ 0.05) Friedman과 Wilcoxon signed-rank 및 Mann Whitney 검증을, 정규성을 만족한 경우 paired- $t$ test를 시행하였다. Statistical product and service solution 12.0 (SPSS 12.0 version, SPSS Inc., Chicago, IL, USA)을 사용하여 유의수준 0.05 를 기준으로 분석하였다.

\section{RESULTS}

\section{인공와우 사용자의 바이모달 혜택}

인공와우 사용자 전체 20 명을 대상으로 보청기만 착용한 경 우, 인공와우만 착용한 경우, 바이모달 착용 경우 세 가지 조건 에서 조용한 상황과 소음 상황 $(5,10 \mathrm{~dB} \mathrm{SNR)}$ 의 문장 검사, 단
음절어 검사, 이야기 이해 검사를 시행한 결과 대상자마다 다 양한 개인 차이를 보였다. 시행한 모든 검사에서 보청기, 편측 인공와우, 바이모달의 착용 순으로 평균값이 증가하였으며 (Figure 2) 바이모달 착용 시 보청기 또는 인공와우만 착용했을 때보다 더 향상된 평균값을 보였다 $(p<0.05$, Friedman test). 편측 인공와우와 바이모달 착용 조건만을 비교했을 때 바이모 달은 조용한 상황 문장 검사에서 평균 7.1\% points $(p<0.05$, Wilcoxon signed-rank test)와 단음절 단어 검사에서 평균 $7.5 \%$ points ( $p<0.05$, Wilcoxon signed-rank test) 향상을 보 였다. $10 \mathrm{~dB} \mathrm{SNR}$ 과 $5 \mathrm{~dB} \mathrm{SNR}$ 및 이야기 이해 검사에서는 각 각 평균 $6.6 \%, 6.3 \%, 8 \%$ points 향상을 보였으나 통계적으로 유 의하지 않았다 $(p>0.05$, Wilcoxon signed-rank test).

Figure 3은 전체 대상자의 주관적 음질 검사 평균을 보여준 다. 부드러움, 명료함, 풍부함, 거리감, 쾌적함, 전체적인 느낌의 6 개 항목의 음질 평가에서 보청기 또는 인공와우만을 착용한 상태보다 바이모달 조건에서 향상된 평균을 보였다 $(p<0.05$, Friedman test). 바이모달 효과를 확인하기 위해 편측 인공 와우와 바이모달 조건을 비교한 결과 각 6 개 음질 항목에서 0.5 0.9점(평균 0.7점)의 향상을 보였다 $(p<0.05$, Wilcoxon signed-rank test).

\section{인공와우 사용자의 보청기 적합}

13 명 바이모달 사용자의 보청기 착용 기간은 약 2 34년까지 다양하였고 사용하고 있는 보청기와(Table 1) 보청기를 착용하 고 있는 귀의 잔존 청력과 기능이득에서도 개인마다 차이가 있 었다(Figure 1). 7명 편측 인공와우 착용자 중 4명은 과거 8 20 년 동안 보청기를 착용한 경험이 있으나 현재는 착용하고 있지 않았으며 나머지 3 명은 보청기 사용 경험이 거의 없는 것으로
Figure 2. Percentage of correct scores across three test conditions for total participants. Error bars indicate standard errors. ${ }^{*} p<0.05$. HA: hearing aid, $\mathrm{Cl}$ : cochlear implant, CVC: consonant-vowelconsonant, SNR: signal to noise ratio.

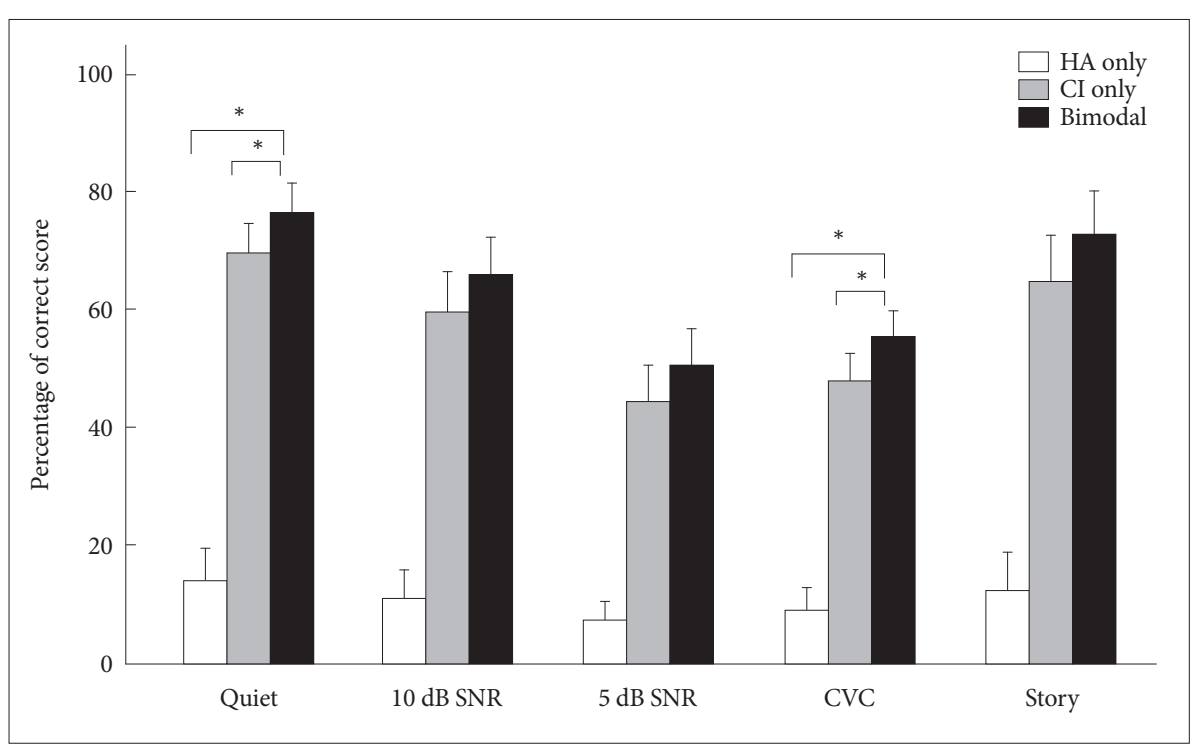




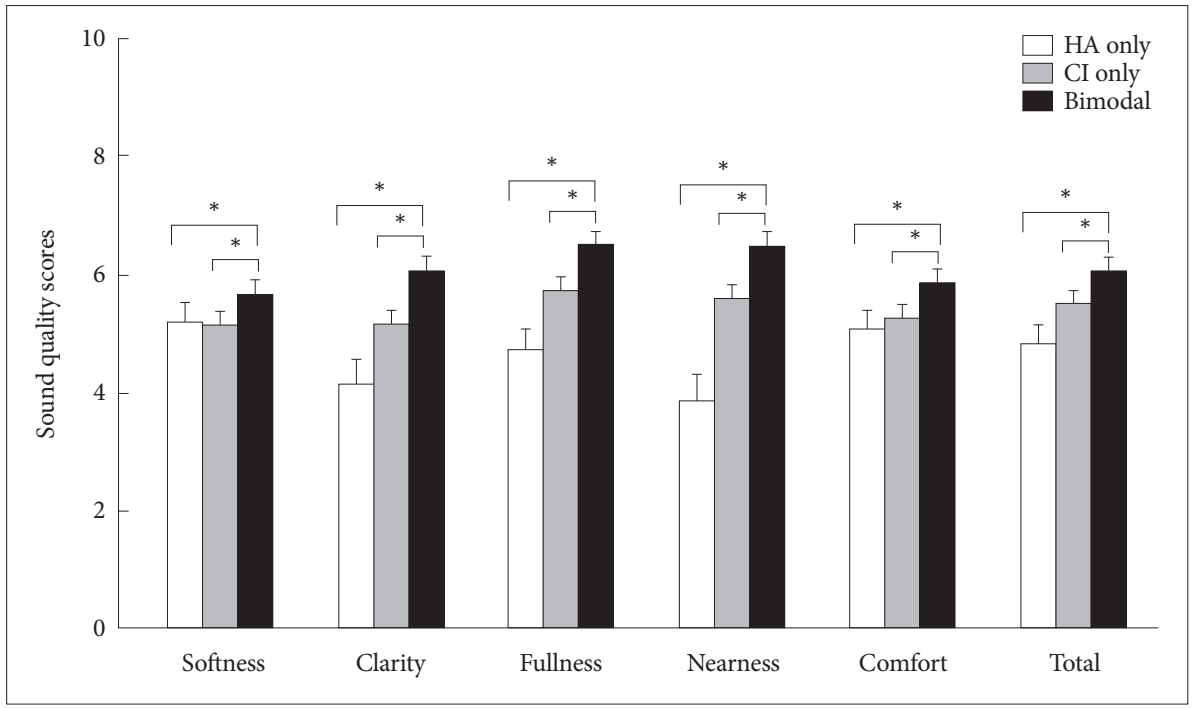

Figure 3. Sound quality scores across three test conditions for total participants. Error bars indicate standard errors. ${ }^{*} p<$ 0.05. HA: hearing aid, $\mathrm{Cl}$ : cochlear implant.
보고하였다. 13 명의 바이모달 사용자 중 8 명(약 $62 \%$ )은 현재 적 합 상태에 만족하지 못하거나 소리가 작다고 보고하였고 기능 이득이 적게 나타났으며, 바이모달 사용자의 대부분이 자신의 청력 상태에 적합하지 않은 보청기를(예, 오픈형 보청기) 사용 하는 것으로 나타났다. 바이모달 사용자와 편측 인공와우 사용 자의 보청기 착용 귀의 250 2,000 Hz까지의 청력에서 바이모 달 사용자가 편측 인공와우 사용자의 청력보다 평균 약 30 20 $\mathrm{dB}$ 더 좋은 것으로 나타났으나 $(p<0.05)$ 두 그룹 간 보청기 착 용 후의 주파수별 청력과 기능이득을 비교했을 때 차이가 없었 다 $(p>0.05)$.

바이모달 사용자 12 명과 편측 인공와우 사용자 6 명을 대상 으로 $50,65,80 \mathrm{~dB}$ SPL의 입력음을 제시한 상태에서 실이 측 정을 시행하고 입력음에 따른 목표이득과 실이삽입이득을 비 교한 결과 두 그룹 모두 각 제시 음압 조건에서 실이삽입이득 이 목표이득 평균보다 낮았다(Figure 4, 5). 바이모달 사용자의 경우 입력음 $50 \mathrm{~dB} \mathrm{SPL}$ 의 목표이득은 각 주파수별로 평균 2.42 61.2 dB이었고 삽입이득은 $16.8 \sim 41.3 \mathrm{~dB}$ 로 나타났다. 입 력음 $60 \mathrm{~dB}$ SPL의 각 주파수별 목표이득은 평균 0.98 54 dB 였으며 삽입이득은 평균 $13.5 ~ 39.8 \mathrm{~dB}$ 이었다. 입력음 $80 \mathrm{~dB}$ $\mathrm{SPL}$ 에서 목표이득은 $2.18 \sim 45.8 \mathrm{~dB}$, 삽입이득은 9.25 28.6 dB 에서 나타났다. $65 \mathrm{~dB}$ SPL 입력음의 4,000, 6,000, 8,000 Hz와 $80 \mathrm{~dB} \mathrm{SPL}$ 입력음의 $8,000 \mathrm{~Hz}$ 를 제외한 모든 주파수에서 삽 입이득이 목표이득보다 작았다 $(p<0.05)$.

편측 인공와우 사용자의 실이 측정 결과, 입력음 $50 \mathrm{~dB} \mathrm{SPL}$ 의 목표이득은 7.84 72.34 dB이었고 삽입이득은 20.5 46.8 dB 로 나타났고, $65 \mathrm{~dB}$ SPL에서 목표이득은 2.78 $67.25 \mathrm{~dB}$, 삽입 이득은 23.5 40.5 dB로, $80 \mathrm{~dB}$ SPL에서 목표이득은 7.8 57.2 $\mathrm{dB}$, 삽입이득은 13 28.4 dB로 나타났다. $55 \mathrm{~dB}$ SPL 입력음의
$8,000 \mathrm{~Hz}, 65 \mathrm{~dB}$ SPL 입력음의 4,000, 6,000, 8,000 Hz 및 80 $\mathrm{dB}$ SPL 입력음의 $4,000,8,000 \mathrm{~Hz}$ 를 제외한 모든 주파수에서 삽입이득이 목표이득보다 작았다 $(p<0.05$, paired $t$ test).

\section{DISCUSSIONS}

본 연구에서는 인공와우 사용자를 대상으로 보청기, 인공와 우, 바이모달을 착용하였을 때의 말지각과 음질 인지에서의 바 이모달 혜택을 알아보고 바이모달 보청기 적합 상태를 파악하 여 바이모달 보청기 적합과 적합 후 평가 지침에 활용하고자 하 였다. 실험에 참여한 인공와우 사용자는 방음실 내 정면에서 65 $\mathrm{dB} \mathrm{SPL}$ 로 제시되는 조용한 상황과 소음 상황에서의 문장 및 단 음절 단어를 듣고 따라 말하였으며 이야기 검사에서는 이야기 를 듣고 이야기 내용에 대한 질문에 답하도록 하였다. 또한 6 개 음질 항목에 대한 주관적 평가를 측정하였다. 착용 조건에 따라 전체 20명을 대상으로 분석하였을 때 인공와우만 착용했을 때 보다 조용한 상황의 문장과 단어 검사에서 약 $7 \%$ points의 의 미 있는 바이모달 효과를 보였고 음질 검사에서도 향상을 보였 다. 또한 13 명 바이모달 사용자 중 8 명이 보청기 소리가 작거나 적합 상태에 만족하지 않았으며 실이 측정에서는 삽입이득이 목표이득보다 평균 약 $10 ~ 16 \mathrm{~dB}$ 낮았다.

본 연구의 결과는 조용한 상황의 문장과 일음절 단어에 대 해서만 약 $7 \%$ points의 향상을 보여 선행 연구에 비해 비교적 적은 바이모달 혜택을 보였다. 한 예로 선행 연구에서는 조용한 상황 단어 검사에서 약 $10 ~ 15 \%$ points, 소음 상황 문장 검사에 서 약 20\% points 향상을 보고하였다(Gifford et al., 2007; Dorman et al., 2008; Potts et al., 2009; Berrettini et al., 2010). 이 처럼 감소된 바이모달 이득은 본 연구에 참여한 대상자들의 바 


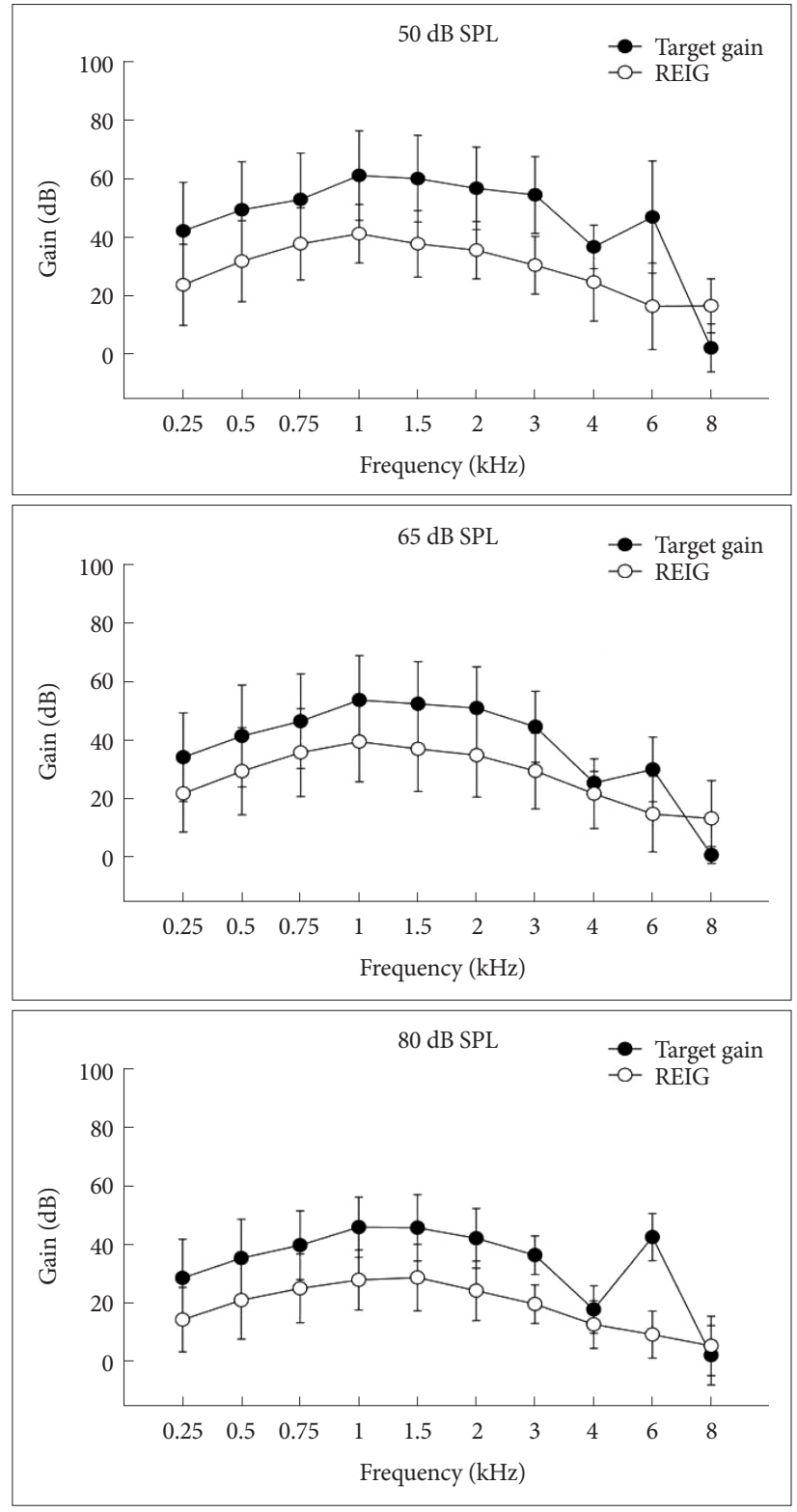

Figure 4. Differences between target gains and real ear insertion gains of 12 bimodal participants. SPL: sound pressure level, REIG : real ear insertion gain.

이모달 적합 문제와 관련하여 생각해볼 수 있다. 실제로 바이 모달 착용자 13 명 중 8 명은 현재 본인의 바이모달 적합에 대한 불만족과 소리 크기에 대한 문제점을 제시하였으며, 대부분의 바이모달 참여자도 바이모달 착용 시 주관적으로 느껴지는 효 과가 거의 없다고 보고하였다. 연구 참여자의 바이모달 보청기 적합과 관련된 문제점들은 크게 개인의 청력 상태에 맞지 않는 보청기의 선택, 보청기 이득의 저하, 보청기와 인공와우 양 귀 간 균형 여부, 바이모달 적합 및 사후관리의 부재, 바이모달 적 합을 책임지는 전문가의 부족 또는 인공와우와 보청기 전문가 간의 소통, 협업의 부재로 정리할 수 있다. Siburt \& Holmes
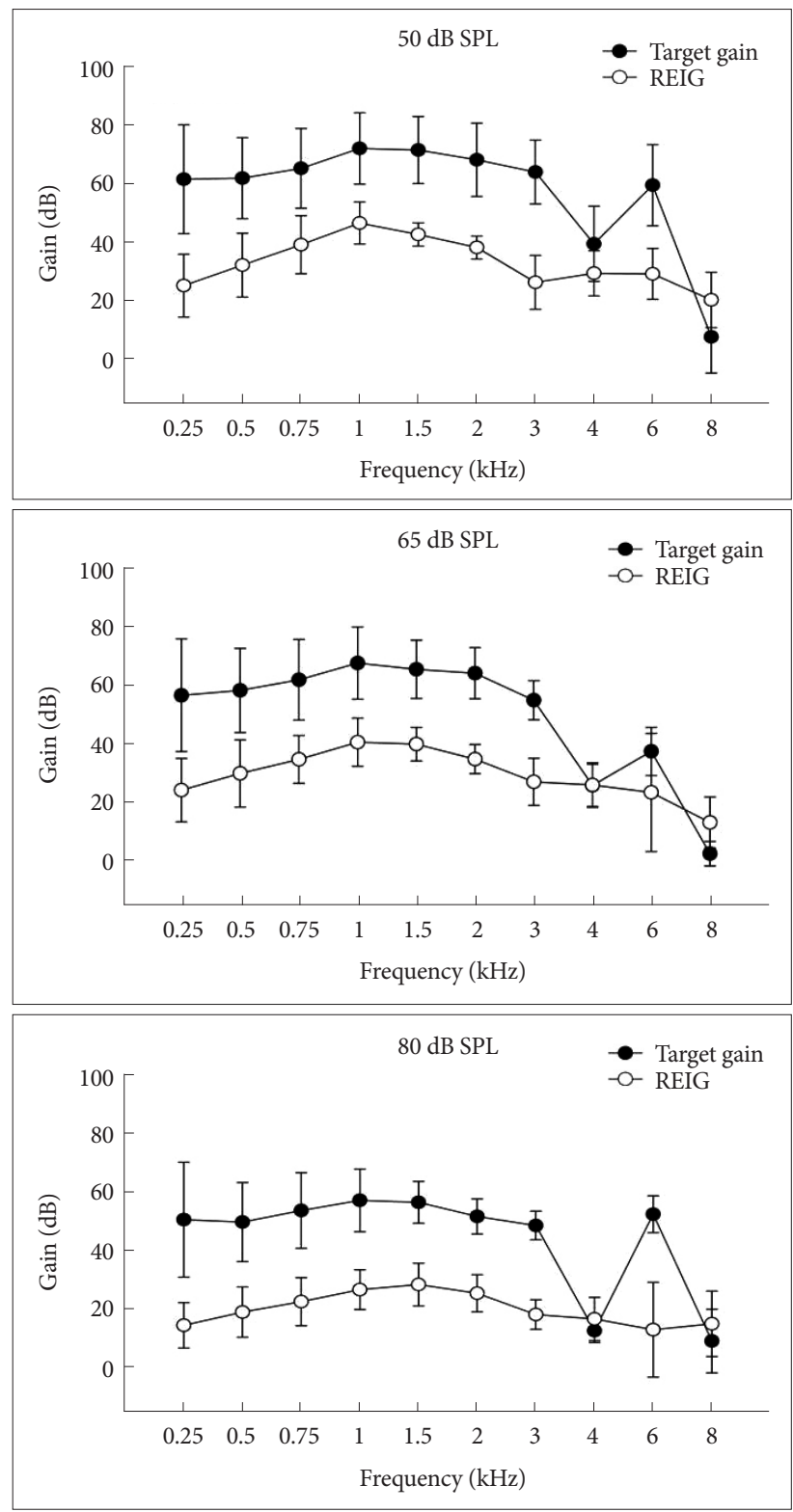

Figure 5. Differences between target gains and real ear insertion gains of 6 unilateral cochlear implant participants. SPL: sound pressure level, REIG : real ear insertion gain.

(2015)에 의하면 미국 인공와우 매핑 전문가의 $36 \%$ 만 바이모 달 보청기 적합이 가능하였고 대부분이 다른 센터에서 바이모 달 보청기 적합을 시행하고 있음을 보고하였다. 또한 바이모달 보청기 적합 시 다양한 적합 공식을 적용하고 있었으며 오직 응 답자의 $29 \%$ 만 실이 측정을 항상 사용하고 $22 \%$ 의 응답자는 실 이 측정을 전혀 사용하고 있지 않다고 응답하여 바이모달 적합 관리의 책임 인력이 부족하고 바이모달 적합이 제대로 이루어지 고 있지 않음을 언급하였다. 본 연구의 결과는 Siburt \& Holmes (2015)가 기술한 것처럼 연구 참여자들의 바이모달 적합관리가 제대로 이루어지고 있지 않았음을 확인할 수 있었다. 


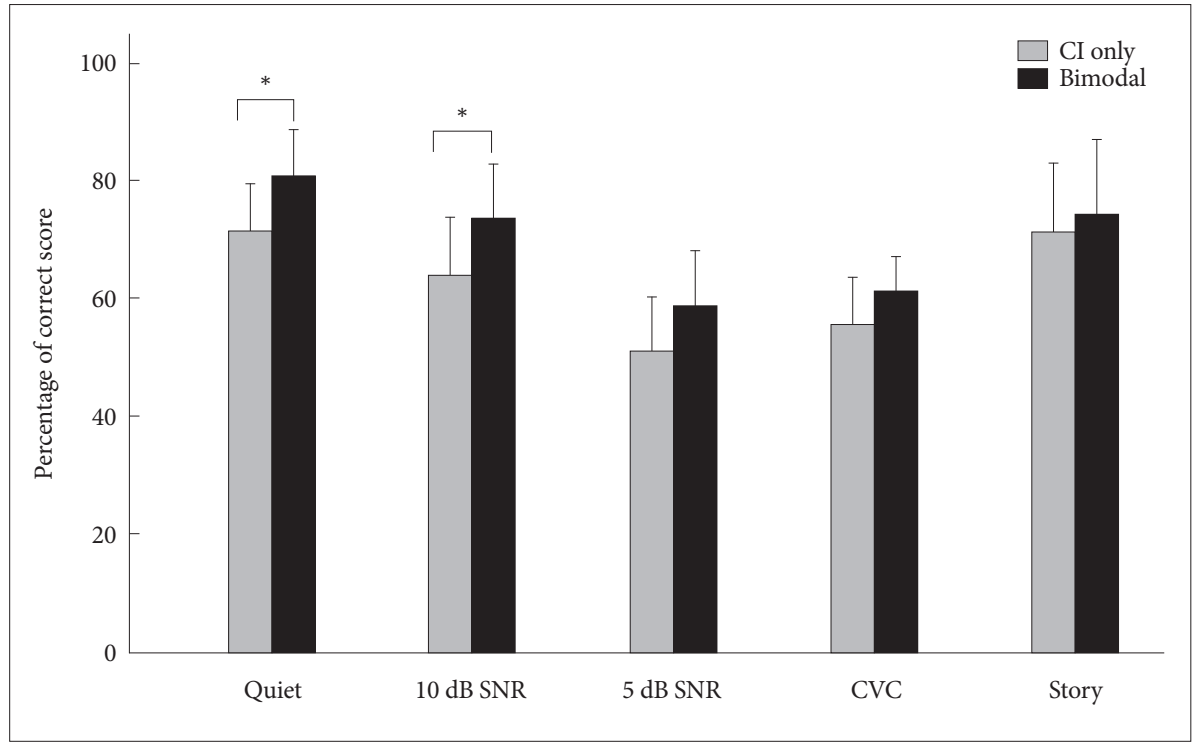

Figure 6. Percentage of correct scores across three test conditions for unilateral $\mathrm{Cl}$ participants. Error bars indicate standard errors. ${ }^{*} p<0.05$. Cl: cochlear implant, CVC: consonant-vowel-consonant, SNR: signal to noise ratio.
한 가지 고무적인 사실은 13 명 바이모달 사용자 모두가 현재 보청기를 꾸준히 착용하고 있다는 것이다. 하루 $1 \sim 4$ 시간 동안 보청기를 착용한다는 2 명을 제외한 11 명은 하루 8 시간 이상 보 청기를 착용하는 것으로 보고하여 보청기 적합과 사후관리가 좀 더 강화된다면 바이모달 효과가 지금보다는 좀 더 향상될 수 있을 것으로 생각된다. 또한 바이모달 사용자에 비해 청력이 좋 지 않은 편측 인공와우 사용자가 보청기를 착용한 뒤 바이모달 효과를 측정했을 때 조용한 상황과 $10 \mathrm{~dB} \mathrm{SNR}$ 소음 상황에서 약 $10 \%$ points의 바이모달 효과를 보였다(Figure 6). 이는 편측 인공와우 사용자도 보청기 착용 효과가 있을 수 있으며 이에 대 한 체계적 관리의 필요성 또한 고려해 볼 수 있음을 보여준다. Warren \& Dunbar(2018)도 특별한 예외사항이 없다면 편측 인 공와우 사용자들이 보청기를 착용하도록 추천하고 있다.

바이모달 착용 상태에서 음질 등을 포함한 주관적 만족도를 평가하는 것은 바이모달 평가와 적합관리에 포함되어야 할 항 목으로 생각된다. 본 연구에서도 바이모달 착용 시 주관적 음 질 평가가 향상되었다. 바이모달 사용자의 음악지각 측면의 향 상은 선형 여러 연구에서 보고된 바 있는데 본 연구에서 음질 검사를 위해 음악 자극을 사용한 것도 음질 향상에 영향을 미 쳤을 것으로 생각된다. 주관적 음질을 좀 더 체계적으로 판단 할 수 있는 다양한 음질 검사 도구에 대한 연구 또한 앞으로 진 행되어야 할 것으로 생각된다. 또한 음질 검사 바이모달 혜택을 측정할 수 있는 주관적 설문 검사도 활용 가능하다.

Warren \& Dunbar(2018)는 바이모달 청지각에서 어려움을 양 귀 간 전기와 음향 역동 범위의 불일치, 각 기기 간 음량 크 기 매치의 한계, 양 귀 간 스펙트럴 불일치로 설명하였다. 또한 바이모달 적합관리 지침과 관련하여 적절한 보청기 적합 공식
의 활용(예, NAL-NL1, NAL-revised, profound)과 대상자의 잔존 청력과 청력 형태에 따른 주파수 범위의 설정, 와우 사영역 검사의 활용, 양 귀 간 신호 처리 특성에 대한 고려(예, 자동이득 제어 설정의 매치 여부)가 필요함을 기술하였다. 인공와우 매핑 전문가와 보청기 적합 전문가가 다르거나 서로 의사소통이나 협 업이 부족한 경우도 바이모달 적합관리가 제대로 이루어지지 않는 문제점을 야기할 수 있으며 바이모달 사용자에게 좀 더 전 반적인 적합관리 서비스를 제공해줄 수 있는 지침과 전문가의 협업이 필요함을 강조 하였다. 향후 바이모달 적합에서 좀 더 체 계적인 방법들이 시행되고 효과를 평가하여 바이모달 사용자들 의 혜택이 증가하고 만족도가 향상될 수 있기를 기대한다.

중심 단어 : 바이모달청취·바이모달혜택·바이모달적합·바이모 달적합 프로토콜.

\section{Ethical Statement N/A}

\section{Acknowledgments}

The authors are grateful to those who participated in this study.

\section{Declaration of Conflicting Interests}

There are no conflict of interests.

\section{Funding}

This work was supported by the Ministry of Education of the Republic of Korea and the National Research Foundation of Korea (2019S1A5A 8038153).

\section{Author Contributions}

Conceptualization: all authors. Data curation: Leehwa Park. Formal analysis: Soo Hee Oh. Funding acquisition: Soo Hee Oh. Investigation: Leehwa Park. Methodology: Soo Hee Oh. Project administration: Soo 
Hee Oh. Resources: Leehwa Park. Supervision: Soo Hee Oh. Validation: Soo Hee Oh. Visualization: Leehwa Park. Writing_original draft: Leehwa Park. Writing_review \& editing: Soo Hee Oh. Approval of final manuscript: all authors.

\section{ORCID iDs}

Leehwa Park

Soo Hee Oh

https://orcid.org/0000-0002-1147-6333

https://orcid.org/0000-0002-3745-1484

\section{REFERENCES}

Advanced Bionics. (2016). Optimizing hearing for listeners with a cochlear implant and contralateral hearing aid. Retrieved from https://advancedbionics.com/content/dam/advancedbionics/Documents/Regional/US/ libraries/bimodal/Bimodal-Fitting-Formula-Whitepaper.pdf.

Bahng, J. \& Oh, S. H. (2020). A literature review of bimodal fitting. Audiology and Speech Research, 16(4), 265-275.

Berrettini, S., Passetti, S., Giannarelli, M., \& Forli, F. (2010). Benefit from bimodal hearing in a group of prelingually deafened adult cochlear implant users. American Journal of Otolaryngology, 31(5), 332-338.

Byrne, D., Dillon, H., Ching, T., Katsch, R., \& Keidser, G. (2001). NAL-NL1 procedure for fitting nonlinear hearing aids: Characteristics and comparisons with other procedures. Journal of the American Academy of Audiology, 12(1), 37-51.

Ching, T. Y., Incerti, P., \& Hill, M. (2004). Binaural benefits for adults who use hearing aids and cochlear implants in opposite ears. Ear and Hearing, 25(1), 9-21.

Cochlear Limited. (2017). Bimodal fitting guide. Retrived from https://www. cochlear.com/8d1b8caa-20de-4641-af10-22bdcb5ae291/FUN2870-ISS1JUN17-Bimodal-Fitting-Guide.pdf?MOD=AJPERES\&CVID=nm9LSD.

Devocht, E. M. J., Janssen, A. M. L., Chalupper, J., Stokroos, R. J. S., \& George, E. L. J. (2017). The benefits of bimodal aiding on extended dimensions of speech perception: Intelligibility, listening effort, and sound quality. Trends in Hearing, 21, 2331216517727900.

Dorman, M. F., Gifford, R. H., Spahr, A. J., \& McKarns, S. A. (2008). The benefits of combining acoustic and electric stimulation for the recognition of speech, voice and melodies. Audiology and Neurotology, 13(2), 105-112.

Farinetti, A., Roman, S., Mancini, J., Baumstarck-Barrau, K., Meller, R., Lavieille, J. P., et al. (2015). Quality of life in bimodal hearing users (unilateral cochlear implants and contralateral hearing aids). European Archives of Oto-Rhino-Laryngology, 272(11), 3209-3215.

Gifford, R. H., Dorman, M. F., McKarns, S. A., \& Spahr, A. J. (2007). Combined electric and contralateral acoustic hearing: Word and sentence recognition with bimodal hearing. Journal of Speech, Language, and Hearing Research, 50(4), 835-843.

Keidser, G., Dillon, H., Flax, M., Ching, T., \& Brewer, S. (2011). The NALNL2 prescription procedure. Audiology Research, 1(1), 88-90.

Kim, J. S., Shin, E. Y., Shin, H. W., \& Lee, K. D. (2011). Development of Korean Consonant Perception Test. The Journal of the Acoustical Society of Korea, 30(5), 295-302.

Kim, K. H. \& Lee, J. H. (2018). Evaluation of the Korean Matrix Sentence
Test: Verification of the list equivalence and the effect of word position. Audiology and Speech Research, 14(2), 100-107.

Kong, Y. Y., Stickney, G. S., \& Zeng, F. G. (2005). Speech and melody recognition in binaurally combined acoustic and electric hearing. The Journal of the Acoustical Society of America, 117(3), 1351-1361.

Kong, Y. Y. \& Carlyon, R. P. (2007). Improved speech recognition in noise in simulated binaurally combined acoustic and electric stimulation. The Journal of the Acoustical Society of America, 121(6), 3717-3727.

Lim, E. H. \& Bahng, J. (2016). Preliminary study for development of auditory training tool using story and question. Audiology and Speech Research, 12(2), 109-114.

Moore, B. C. \& Alcántara, J. I. (2001). The use of psychophysical tuning curves to explore dead regions in the cochlea. Ear and Hearing, 22(4), 268-278.

Moore, B. C., Glasberg, B. R., \& Stone, M. A. (2004). New version of the TEN test with calibrations in AB HL. Ear and Hearing, 25(5), 478-487.

Moore, B. C., Huss, M., Vickers, D. A., Glasberg, B. R., \& Alcántara, J. I. (2000). A test for the diagnosis of dead regions in the cochlea. British Journal of Audiology, 34(4), 205-224.

Oticon. (2015). Bimodal hearing aid fitting guidelines. Retrieved from https:// www.oticon.com/-/media/oticon-us/main/download-center/whitepapers/18922-sensei-sp-bimodal-fitting-whitepaper.pdf.

Potts, L. G., Skinner, M. W., Litovsky, R. A., Strube, M. J., \& Kuk, F. (2009). Recognition and localization of speech by adult cochlear implant recipients wearing a digital hearing aid in the nonimplanted ear (bimodal hearing). Journal of the American Academy of Audiology, 20(6), 353373.

Scherf, F. W., Arnold, L. P., \& Poster presentation at the 12th International Conference on Cochlear Implants and Other Implantable Auditory Technologies, ESPO 2012, Amsterdam, the Netherlands, SFORL 2012, Paris, France. (2014). Exploring the clinical approach to the bimodal fitting of hearing aids and cochlear implants: Results of an international survey. Acta Oto-Laryngologica, 134(11), 1151-1157.

Siburt, H. W. \& Holmes, A. E. (2015). Bimodal programming: A survey of current clinical practice. American Journal of Audiology, 24(2), 243-249.

Van Loon, M. C., Smits, C., Smit, C. F., Hensen, E. F., \& Merkus, P. (2017). Cochlear implantation in adults with asymmetric hearing loss: Benefits of bimodal stimulation. Otology and Neurotology, 38(6), e100-e106.

Veugen, L. C., Chalupper, J., Snik, A. F., Opstal, A., \& Mens, L. H. (2016). Matching automatic gain control across devices in bimodal cochlear implant users. Ear and Hearing, 37(3), 260-270.

Vroegop, J. L., Goedegebure, A., \& van der Schroeff, M. P. (2018). How to optimally fit a hearing aid for bimodal cochlear implant users: A systematic review. Ear and Hearing, 39(6), 1039-1045.

Vroegop, J. L., Homans, N. C., van der Schroeff, M. P., \& Goedegebure, A. (2019). Comparing two hearing aid fitting algorithms for bimodal cochlear implant users. Ear and Hearing, 40(1), 98-106.

Warren, S. E. \& Dunbar, M. N. (2018). Bimodal hearing in individuals with severe-to-profound hearing loss: Benefits, challenges, and management. Seminars in Hearing, 39(4), 405-413.

Yoon, Y. S., Shin, Y. R., Gho, J. S., \& Fu, Q. J. (2015). Bimodal benefit depends on the performance difference between a cochlear implant and a hearing aid. Cochlear Implants International, 16(3), 159-167. 